\title{
When there is no forest left: fragmentation, local extinction, and small population sizes in the Sri Lankan western purple-faced langur
}

\author{
L. Parker, V. Nijman, K. A. I. Nekaris* \\ School of Social Sciences and Law, Department of Anthropology and Geography, Oxford Brookes University, \\ OX3 0BP Oxford, UK
}

\begin{abstract}
The western purple-faced langur Trachypithecus vetulus nestor is a Critically Endangered primate endemic to Sri Lanka according to the International Union for Conservation of Nature (IUCN). Its population decline is inferred mainly due to vast habitat loss. Few recent data are available regarding its distribution or abundance. The aim of our study was to assess the conservation status of T. V. nestor throughout its known historical range by establishing presence/absence and correlating these data with semi-structured interviews determining human perceptions and threats. Twenty-six sites were investigated, with presence of T. v. nestor being confirmed at 11 and indicated through questionnaires only at 2 additional sites. The present distribution of $T$. $v$. nestor is severely fragmented both locally and regionally. More than half of the populations comprised 1 or 2 groups only and, being isolated in a matrix of urban landscapes, are close to unviable. Conflicts between local people and T. v. nestor were identified at such sites, where reports of troops crop-raiding gardens and plantations were associated with negative perceptions. Consequences for crop-raiding langurs ranged from shouting to (infrequently) shooting and killing by dogs. Negative views towards $T$. $V$. nestor were significantly related to the length of time they spent in anthropogenic landscapes, while more positive views were significantly associated with the length of time T. $v$. nestor spent in forested areas. Evidence of local extinctions means that the remaining, yet increasingly fragmented habitat of the highly arboreal T. V. nestor is critical for survival. Intervention to manage this human-wildlife conflict is vital. An integrated approach using international and local conservation authorities is highly recommended.
\end{abstract}

KEY WORDS: Habitat loss · Conservation · Sri Lanka · Western purple-faced leaf monkey • Trachypithecus (Semnopithecus) vetulus nestor

\section{INTRODUCTION}

Sri Lanka and the Western Ghats of India have together been identified as one of the 25 'biodiversity hotspots' in the world (Myers et al. 2000), and one of 11 global 'hyperhot' hotspots (Brookes et al. 2002). Sri Lanka's Wet Zone contains a large proportion of the island's endemic flora and fauna (Crusz 1973, Dittus 1977, Erdelen 1988), and yet this area contains only $5 \%$ of Sri Lanka's protected areas (Crusz 1973, Santiapillai \& Jayewardene 1999). Most of the protected forest occurs in 5 highly fragmented reserves and the remainder of forest exists as around 60 small privately owned fragments surrounded by human habitation (Weerakoon 2001).

Four allopatric subspecies of purple-faced langurs Trachypithecus (Semnopithecus) vetulus are currently recognised, all differing in cranial and pelage characteristics, as well as body size (Philips 1981, Groves 2001, Brandon-Jones et al. 2004). Endemic to the Wet Zone of Sri Lanka, the western purple-faced langur T. V. nestor is listed as Critically Endangered $(\mathrm{A} 2 \mathrm{~cd}+3 \mathrm{~cd}+4 \mathrm{~cd})$ on the International Union for Conservation of Nature (IUCN) Red List (IUCN 2006). Forest cover in Sri Lanka has declined drastically since the late $1950 \mathrm{~s}$ and the area of occurrence of T. V. nestor has 
been reduced to a highly fragmented $1900 \mathrm{~km}^{2}$ area in the western Wet Zone (Molur et al. 2003). Subsequently, the subspecies has been included on the Top 25 Most Endangered Primates in the World list (Mittermeier et al. 2006, 2007).

Molur et al. (2003) list the threats to this taxon as being infringement on range by crop plantations, grazing, shifting agriculture, timber and roads, soil loss/erosion and deforestation, poisoning mainly to prevent crop raiding, and hunting for traditional medicine and food. The projected population of Trachypithecus vetulus nestor is estimated to decrease by over $80 \%$ over the next 3 generations (Dela et al. 2002 in IUCN 2006). Severe deforestation in its range has resulted in many groups being forced to live in remaining tree patches in urbanised areas, such as gardens and tree crop plantations (Dela 2004, Mittermeier et al. 2006, Eschmann 2007). Recently, Rudran (2007) published the results of a $10 \mathrm{~d}$ vehicle survey of parts of the distribution range of $T$. v. nestor and recorded 9 groups of the species at 12 sites. Likewise, Nahallage et al. (in press) surveyed in the area from 2004 to 2007 and recorded 5 groups at 3 sites. In 2006, we conducted a more extensive 3 mo survey, covering the entire known distribution range of the species, collecting data additional to those reported by Rudran (2007) and Nahallage et al. (in press). Furthermore, in 2007, we studied one of the largest populations. The aim of the survey was to gather data on the distribution and population sizes of the species, and to assess the perceptions of humans towards these primates in order to inform conservation policies.

\section{MATERIALS AND METHODS}

We selected 27 potential survey sites from historic and more contemporary sources (John 1795, Forbes 1840, Haeckel 1883, Hill 1934, Eisenberg \& McKey 1970, Philips 1981, Molur et al. 2003, Dela 2004) and surveyed them from May to July 2006 for a total of $53 \mathrm{~d}$. In order to assess the presence or absence of langurs in an area, we used a combination of direct observations, vocal recordings, and data from local people (Ross \& Reeve 2003). In May to July 2007 we studied one of the larger populations for an additional $129 \mathrm{~d}$ to obtain data on group sizes and threats (Eschmann et al. 2008).

Each historical locale was visited and, through semistructured interviews, assessed for the presence/ absence of remaining langur populations (Strayer 1999, Gaidet-Drapier et al. 2006, Pollock 2006). On average, 28 interviews were conducted for each location, with at least 16 interviews at sites where we did not find the species to be present, yielding a total of
735 interviews. Interviews were kept short (typically lasting between 5 and $10 \mathrm{~min}$ ) and were carried out at the respondents' homes, farms or monasteries. To ensure independence of data, each interview was conducted separately (Lammertink et al. 2003). The questionnaires were constructed simultaneously to collect data on human attitudes towards the langurs (Hill 1997). The questions pertaining to the present study are listed in Appendix 1.

Irrespective of whether or not the interviews identified presence of Trachypithecus vetulus nestor, the site was surveyed for confirmation and, if the species was present, we collected data on group sizes. Their rarity and their occurrence in privately owned locations (such as gardens and plantations) did not allow us to conduct standardised surveys such as line transects (Buckland et al. 1993). Non-systematic excursions on foot following available trails through villages, agricultural plots and forest patches were made. Their loud daily morning calls and habituation to humans in most areas (Eschmann et al. 2008) allowed for easy confirmation of presence. Group sizes were estimated by following a group as long as necessary to be certain that all individuals were observed; when this was not possible, we estimated a minimum group size (that is the number of individuals actually observed plus additional members that vocalised but that were clearly not among the individuals in sight) and a maximum group size (as with minimum group size adding individuals that were observed not simultaneously with the main group but that in all likelihood were not observed before, and individuals that were detected by other means). For each site we provide a range of population estimates, with the upper end value used in the analysis. Compared to other langurs (Semnopithecus, Trachypithecus, Presbytis) we have studied (Nijman 2000, 2004, Nekaris \& de Silva Wijeyeratne 2008, V. Nijman $\&$ K. A. I. Nekaris unpubl. data), western purple-faced langurs, because of their vocal nature, their partial habituation to human observers, and the visibility in the habitat in which they live, are amongst the easiest to observe. While our population figures are estimates, we are confident that they approximate well the real number of langurs in any given area. For all analyses, non-parametric statistics were used with significance accepted when $\mathrm{p}<0.05$ in a 2-tailed test (Zar 1999).

\section{RESULTS}

\section{Occurrence and population estimates}

We identified 27 sites using records of historical distribution for Trachypithecus vetulus nestor. Four of these sites were not included in our survey: Tabbowa, 
Walagama and Muthurajawala were not visited, and at Panagoda we were not able to pinpoint the exact locality where the langurs could have occurred. Interviews identified 3 additional sites (Pugoda, Nissarana Forest and Talangama Wetlands), yielding a total of 26 survey sites. Due to logistical challenges, 2 sites (Kitulgala and Attidiya-Belanwila Forest) could not be surveyed on foot, but the presence of $T$. $v$. nestor at the latter site was confirmed through interviews. Of the remaining 24 sites, presence of T. V. nestor was confirmed at 11 of them. At a further 2 sites (Kottwawa and Galatura) T. v. nestor was not sighted, but interviews with local people indicated presence (Fig. 1). We report 8 additional sites, from a small area east of Colombo south to the Bolgoda Lakes (Nahallage et al. in press, G. de Silva Wijeyeratne pers. comm.), which we did not visit (Table 1).

The median shortest overland distance between any 2 of the 22 sites where the species is present is some $8 \mathrm{~km}$, with a range of 2 to $60 \mathrm{~km}$. The median survey effort in areas where we did find the species present ( 2 d, total survey effort 129 d) was the same as that of areas where we did not find the species present (total survey effort 22 d). Only 4 out of 14 sites where Trachypithecus vetulus nestor was present (LabugamaKalatuwawa, Nissarana, Ingiriya, and Attidiya-Belanwila) contained forest of more than a few hectares; the other sites were home gardens, villages, or non-forest land. Median maximum population size was a low 20 individuals or 2 groups, with the largest population comprising 72 individuals in 5 groups. No significant relationship was found between survey effort and maximum estimated population size (Spearman's rank correlation, $\mathrm{r}_{\mathrm{S}}=0.14, \mathrm{~N}=13, \mathrm{p}>0.60$ ). The average group size (mean $\pm \mathrm{SD}$ ) was $9.3 \pm 3.9$ individuals (median 8 , range to $19, \mathrm{~N}=23$ ). We found no relationship between survey duration and maximum group size $\left(r_{S}=0.03, N=10, p>0.90\right)$.

\section{Humans and langurs}

Whether or not Trachypithecus vetulus nestor is present in an area is generally well-known to the local people, as a high agreement is found between presence/absence surveys through interviews and through surveys (Fisher's exact probability test, $\mathrm{p}<0.001$ ). A significant relationship between the percentage of respondents indicating presence of $T$. $v$. nestor in their area and maximum estimated population size (Spearman's rank correlation coefficient, $\mathrm{r}_{\mathrm{S}}=0.65, \mathrm{~N}=13, \mathrm{p}=$ 0.02 ) shows that when more langurs occur in the area more people are aware of them.

The number of respondents that reported seeing Trachypithecus vetulus nestor daily is significantly correlated with maximum estimated population size $\left(\mathrm{r}_{\mathrm{S}}=\right.$ $0.63, \mathrm{~N}=13, \mathrm{p}=0.02$ ), but maximum estimated population size has no influence on whether people hold positive or negative views towards protecting the langurs. Where the langurs spent their time according to the interviewees does influence people's perception towards them (Fig. 2). A significant positive relation-
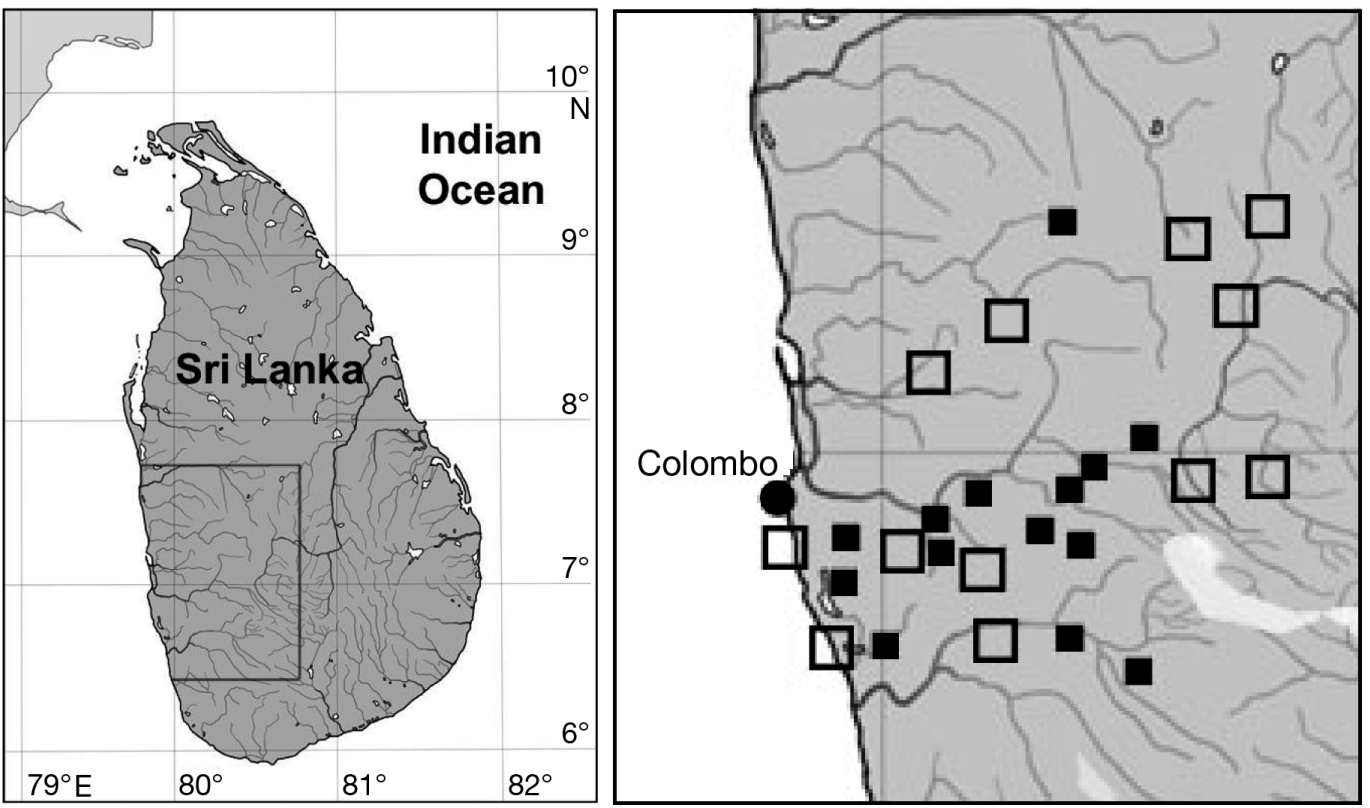

Fig. 1. Trachypithecus vetulus nestor. Localities at which presence was confirmed by sighting or where presence/absence was indicated by interviews. $\mathbf{\square}$ : present; $\square$ : absent. White patches indicate forest reserves 
Table 1. Summary of survey data presenting number of respondents to questionnaires who indicated that Trachypithecus vetulus nestor was present in/near their village, percent who indicated that they saw them on a daily basis, and the number of groups and individuals reported by respondents. Also presented are the results of field surveys. Data for Wijerama, Navinna and Boralasgamuwa from Nahallage et al. (in press); data for Colombo, Koswatta, Battaramulla, Kotikawatta and Bolgoda Lake from G. de Silva Wijeyeratne (pers. comm.). Sites surveyed (with number of respondents) where none of the respondent indicated the presence of langurs and where none were observed during the field survey: Dehiwela (38), Gampaha (39), Gingiathena (30), Homogama (39), Horana (30), Kegalle (34), Kurulukale Sanctuary (16), Mawanella (30), Panadora (36), Pannipitiya (30), Veyangoda (44). -: not applicable; ?: unknown/not assessed

\begin{tabular}{|c|c|c|c|c|c|c|c|}
\hline Site & $\begin{array}{l}\text { Coordinates } \\
\left({ }^{\circ} \mathrm{N},{ }^{\circ} \mathrm{E}\right)\end{array}$ & $\begin{array}{c}\text { No. (\% } \\
\text { indicating } \\
\text { presence) }\end{array}$ & $\begin{array}{l}\text { Respondents } \\
\% \text { reporting } \\
\text { langurs } \\
\text { daily }\end{array}$ & $\begin{array}{c}\text { No. of langur } \\
\text { groups observed } \\
\text { (ind.) }\end{array}$ & $\begin{array}{l}\text { Effort } \\
\text { (d) }\end{array}$ & $\begin{array}{l}\text { Field survey } \\
\text { No. of } \\
\text { langur groups } \\
\text { (ind.) }\end{array}$ & $\begin{array}{l}\text { Langur } \\
\text { pop. } \\
\text { estimate }\end{array}$ \\
\hline Ruwanwella & $07^{\circ} 04^{\prime}, 80^{\circ} 16^{\prime}$ & $30(6)$ & 0 & $1(6)$ & 3 & $1(4)$ & $4-6$ \\
\hline Labugama & $06^{\circ} 51^{\prime}, 080^{\circ} 11^{\prime}$ & $11(64)$ & 29 & $1-2(4-30)$ & 1 & $1(7)$ & $7-30$ \\
\hline Hanwella & $06^{\circ} 55^{\prime}, 80^{\circ} 05^{\prime}$ & $34(9)$ & 33 & $1(5-10)$ & 2 & $1(7)$ & $7-10$ \\
\hline Pugoda & $06^{\circ} 59^{\prime}, 80^{\circ} 07^{\prime}$ & 33 (18) & 50 & $1-2(5-10)$ & 2 & $2(10)$ & 10 \\
\hline Nissarana Forest & $07^{\circ} 00^{\prime}, 80^{\circ} 10^{\prime}$ & $9(44)$ & 25 & $1-3(6-22)$ & 4 & $1(11)$ & $11-22$ \\
\hline Kaduwela & $06^{\circ} 55^{\prime}, 79^{\circ} 59^{\prime}$ & $30(30)$ & 56 & $1-2(4-20)$ & 2 & $2(9)$ & $9-20$ \\
\hline Talangama & $06^{\circ} 54^{\prime}, 79^{\circ} 57^{\prime}$ & $42(73)$ & 79 & $1-4(4-20)$ & 102 & $5(72)$ & 72 \\
\hline Pilayandala & $06^{\circ} 50^{\prime}, 80^{\circ} 10^{\prime}$ & $30(93)$ & 54 & $1-2(8-15)$ & 1 & $2(18)$ & 18 \\
\hline Bandaragama & $06^{\circ} 42^{\prime}, 80^{\circ} 00^{\prime}$ & $30(83)$ & 44 & $1-3(10-40)$ & 1 & $3(21)$ & $21-40$ \\
\hline Ingiriya & $06^{\circ} 44^{\prime}, 80^{\circ} 11^{\prime}$ & $30(47)$ & 50 & $1-4(6-25)$ & 6 & $2(12)$ & $12-25$ \\
\hline Giriulla & $07^{\circ} 20^{\prime}, 80^{\circ} 07^{\prime}$ & $30(17)$ & 0 & $1(4-6)$ & 1 & 1 (call) & $4-6$ \\
\hline Kottwawa & $06^{\circ} 51^{\prime}, 79^{\circ} 58^{\prime}$ & $32(41)$ & 46 & $1-2(5-15)$ & 2 & 0 & $0-15$ \\
\hline Galatura & $06^{\circ} 43^{\prime}, 80^{\circ} 17^{\prime}$ & $18(29)$ & 17 & $2(12-25)$ & 2 & 0 & $0-25$ \\
\hline Attidiya-Bellanwila & $06^{\circ} 53^{\prime}, 79^{\circ} 53^{\prime}$ & $3(100)$ & - & $2-3(4-20)$ & 0 & - & $4-20$ \\
\hline Wijerama & $06^{\circ} 56^{\prime}, 79^{\circ} 52^{\prime}$ & - & - & - & ? & $3(17)$ & 17 \\
\hline Navinna & $06^{\circ} 52^{\prime}, 79^{\circ} 55^{\prime}$ & - & - & - & ? & $1(5)$ & 5 \\
\hline Boralasgamuwa & $06^{\circ} 51^{\prime} 79^{\circ} 54^{\prime}$ & - & - & - & $?$ & $1(7)$ & 1 \\
\hline Colombo & $06^{\circ} 53^{\prime} 79^{\circ} 52^{\prime}$ & - & - & - & - & - & - \\
\hline Koswatta & $06^{\circ} 54^{\prime}, 79^{\circ} 53^{\prime}$ & - & - & - & - & - & - \\
\hline Battaramulla & $06^{\circ} 54^{\prime}, 79^{\circ} 55^{\prime}$ & - & - & - & - & - & - \\
\hline Kotikawatta & $06^{\circ} 56^{\prime} 79^{\circ} 54^{\prime}$ & - & - & - & - & - & - \\
\hline Bolgoda Lake & $06^{\circ} 47^{\prime}, 79^{\circ} 54^{\prime}$ & - & - & - & - & Small populations & - \\
\hline Total & & & & & 129 & & $202-342$ \\
\hline
\end{tabular}

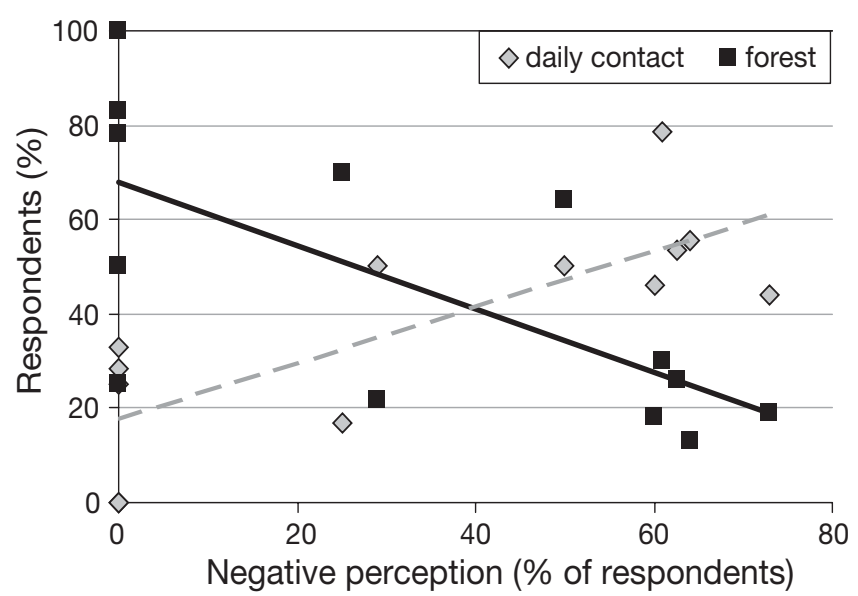

Fig. 2. Trachypithecus vetulus nestor. Percentages of respondents indicating a negative perception towards conservation of $T$. v. nestor in relation to the percentage of respondents that reported observing them daily $(\checkmark)$ and reported forest being the main area where they encountered them $(\boldsymbol{\square})$. Perceptions become more negative when langurs are observed more frequently and near human habitations. Lines represent linear regression ship occurs between the number of people who hold strong negative views towards the langurs and the time the monkeys spent in gardens and farmland $(\mathrm{r}=$ $0.67, \mathrm{~N}=13, \mathrm{p}=0.01$ ). Conversely, a significant positive relationship is evident between the number of people who hold strong positive views towards the langurs and the time the monkeys spent away from anthropogenic landscapes $(\mathrm{r}=0.59, \mathrm{~N}=13, \mathrm{p}=0.03)$.

Most interviewees had positive views towards the monkeys. Positive perceptions included acceptance of monkeys for religious reasons $(11 \%)$ and believing that they were a part of nature (32\%). Indeed, some residents liked the monkeys well enough to keep them as pets, which really should be considered as a threat to these primates. A quarter of all respondents considered Trachypithecus vetulus nestor a nuisance, primarily because of the langurs raiding on items such as jak Arctocarpus heterophylus, rambutan Nephelium lappaceum, banana Musa sexpientum and mango Mangifera indica. Destruction of roof tiles by monkeys and a perception by some respondents $(8 \%)$ that the land belongs to humans also influenced negative attitudes. 
Local people used several deterrents to drive monkeys from their land, including throwing stones, shouting or setting dogs on them, using firecrackers and, albeit infrequently, shooting them. During our study 2 langurs were killed, 1 by a dog and 1 while crossing a power line (Fig. 3). Interviews revealed that 7 langurs were shot by an outsider who had bought land and built a modern house in Talangama (S. Perera pers. comm. to G. de Silva Wijeyeratne). Reportedly in the first 4 mo of 2008, also in Talangama, the dog of a tenant killed at least 3 langurs (K. Conniff pers. comm. to G. de Silva Wijeyeratne).

\section{DISCUSSION}

\section{Fragmentation and local extinctions}

The population of western purple-faced langurs are just a fraction of what they once must have been. Closed canopy forest cover in Sri Lanka decreased steadily from $\sim 80 \%$ in 1880 to $\sim 25 \%$ in 2001 , but within the range of the western purple-faced langur it has been close to 0 in the last decades (Ratnayake et al. 2001). For the Wet Zone as a whole, Kumar et al. (1999) report that just $2 \%$ of undisturbed forest remains. Tea plantations, wet rice fields, rubber plantations, cinnamon and cardamom cultivations, home gardens (Gunatilake 1998), and small remaining forest patches intersperse the villages and towns, constituting the matrix inhabited by western purple-faced langurs.

Of the 38 sites where Trachypithecus vetulus nestor must have been historically present (assuming that the 11 'new' sites were simply overlooked in the past and do not represent recent colonisations), we were able to

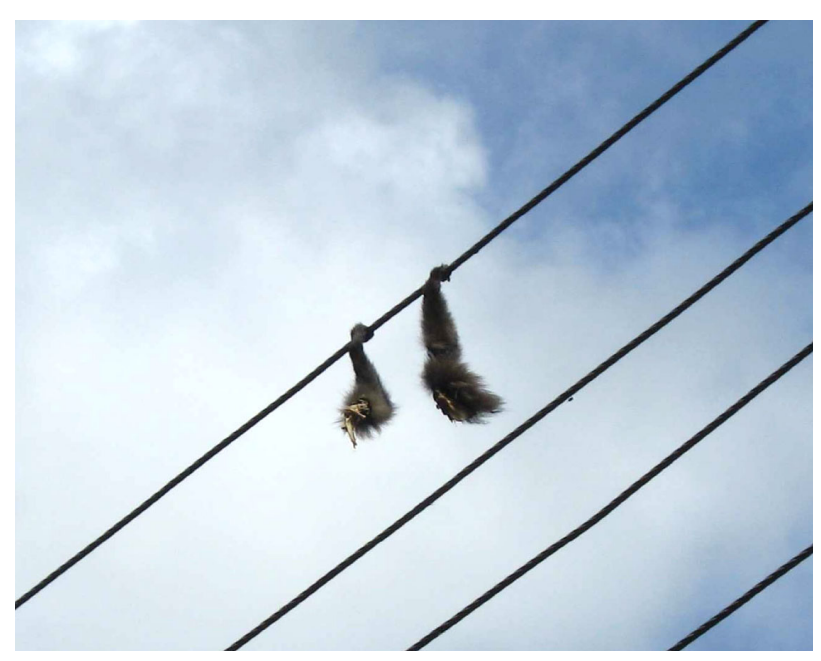

Fig. 3. Trachypithecus vetulus nestor. Remains of an adult male langur killed whilst crossing its habitat on a power line at Talangama Wetlands (Photo: R. Moore) survey 26 but found the species to be present in only 14 of them. Given the ease of detecting T. v. nestor, both by us and by local people, we believe that at some sites they have become locally extinct. Some of these populations may have gone extinct a long time ago, but others more recently. Panadura is a large town interspersed with home gardens that are visited by langurs. Due to the wide area covered by Panadura, we were not able to locate any langurs, but we understand they are still present and are the subject of an ongoing study by Dela (2007). Rudran (2007), during a 10 d survey of T. v. nestor in June and July 2007, reported an absence of this species in Ruwanwella. We did locate a troop comprising at least 4 individuals at this site in 2006. Either T. v. nestor has become extinct at this location within the year between these 2 surveys or Rudran (2007) failed to locate this small isolated troop. Eight of the remaining populations comprise 2 or fewer groups, and even if we somewhat underestimated their population sizes, we fear that these may not be viable even in the short term.

Trachypithecus vetulus generally avoids terrestrial locomotion (Hladik \& Hladik 1972, Eschmann 2007, Moore 2007); hence its ability to move between forest fragments that are not connected by continuous arboreal pathways is likely to be limited. Ground paths, i.e. actual pathways that multiple members used to get from one locality within a troop's home range to another, often consist of local roads or open fields that separate parts of the home range. Ground paths are normally limited in length; those of 5 groups in Talangama, for instance, averaged $13.8 \mathrm{~m}$ (range 5 to $33 \mathrm{~m}$ ), with each group using only 1 ground path in its home range (C. Eschmann \& K. A. I. Nekaris unpubl. data). At sites where forest patches are situated within an urban landscape (e.g. Talangama, Bandaragama, Pilayandala, Kottawa, Kaduwela), T. v. nestor used roofs and electrical cables to disperse, the latter action being a cause of mortality (see also Dela 2004).

The 22 sites where Trachypithecus vetulus nestor is still present are distributed throughout the Wet Zone and each one of them is isolated from other occupied areas by kilometres of unsuitable urbanised land. Furthermore, within some sites (e.g. Pugoda, Ingiriya) habitat patches are isolated from one another, effectively separating groups. Dela (2004) reported low juvenile recruitment rates as a result of fragmentation. Even if we accept that we may have underestimated local population sizes, and we almost certainly must have missed some populations, taking into account demographic and genetic aspects, none of these populations may be viable in the medium long term (Templeton et al. 1990, Li et al. 2007).

Our study is complementary and builds on those recently published by Rudran (2007) and Nahallage et 
al. (in press). There is a great deal of agreement between our results and those of the authors above, but also some disparity. We found 2 and 4 times as many groups as Rudran (2007) and Nahallage et al. (in press), respectively, probably due to more focussed and lengthier surveys on our part. Nahallage et al. (in press) reported an average group size of 5.8 (range 4 to 7, N = 5), whereas Rudran (2007) reported group sizes of Trachypithecus vetulus nestor (4.4, range 1 to $10, \mathrm{~N}$ = 9) to be smaller than those of T. V. monticola (8.9, range 3 to $14, \mathrm{~N}=27$ ) or $T$. $v$. philbricki (8.4, range 3 to $15, \mathrm{~N}=33)$. Our results for $T$. v. nestor $(9.3$, range 4 to $19, N=21$ ) indicate group sizes similar to that of the other taxa, suggesting that habitat loss has not yet influenced this population parameter. We did not find a significant relationship between survey effort and maximum group size, and Rudran's 2007 survey may have underestimated group sizes due to its shortness.

\section{Human-wildlife conflict}

Rudran (2007) suggested that the Buddhist principles of Sri Lankans residing in this area are a primary reason for the persistence of Trachypithecus vetulus nestor, suggesting the killing of langurs is rare (although he reports on the killing of 6 individuals $4 \mathrm{yr}$ earlier). Dela (2004), however, suggests that human tolerance is changing for the worse and cites not only the killing of a member of her study troop as an example, but also highlights poaching, road accidents and killing by residents' dogs as problems. These same threats were apparent in the study of Nahallage et al. (in press), though they added use of $T$. $v$. nestor for medicinal purposes as another threat. In our study area in Talangama, over a $2 \mathrm{yr}$ period, 2 deaths were observed and 10 langurs were reported to be shot or killed by dogs. This may be partially related to outsiders moving into areas where $T$. $v$. nestor is found. Some outsiders do not realise that in areas where the langurs reside it is better to go for flat roofing sheets rather than opting for tiled roofs. The latter are more decorative but easily damaged by langurs jumping on the roofs. Furthermore, G. de Silva Wijeyeratne (pers. comm.) noted that tenants and well-off Sri Lankans who are moving into suburban areas such as Talangama are opting for large, aggressive, dogs, which are status symbols or give them an enhanced sense of security against intruders. Langurs are more likely to be killed by these dogs than the traditional, village dogs, which are smaller in build. Although certainly not comparable to the intolerance shown to primates in other parts of the world (Hill 1997, Fuentes \& Wolfe 2002, Paterson \& Wallis 2005), the total loss of habitat in Sri Lanka's Wet Zone inevitably leads to conflict even with the most tolerant of cultures, and this is exacerbated by people unaccustomed to langurs moving into langur-inhabited areas.

\section{CONCLUSION}

Population numbers of Trachypithecus vetulus nestor are critically low and severely fragmented, both between and within sites. Sri Lankan law protects all primates, including this one. It is obvious, however, that more proactive management of $T . v$. vetulus and its habitat is imperative to its survival. Given the dramatic reduction of habitat in Sri Lanka's Wet Zone in general and the almost complete oblivion of the habitat of $T$. v. nestor, its survival chance is slim. In order to safeguard the species, it is of utmost importance to quickly formulate a conservation strategy. A first priority would be to improve management of those areas already protected where $T$. v. nestor is present (Ingiriya Forest Reserve) and, furthermore, to locate and protect key new areas and corridors within the subspecies' range (Rudran 2007). Protecting the larger populations to the full extent (large being a relative concept here) whether they are living in forested areas (e.g. Labugama-Kalatuwawe) or in villages (e.g. Talangama), and efforts to increase population growth may enhance the prospects of survival for these populations in the medium long term. In areas where langurs and humans do live in close proximity, and where human-langur conflicts have been identified (e.g. Bandaragama), ways to mitigate these conflict peacefully need to be explored. Langurs in almost all areas would benefit from forest restoration and establishing rope bridges between key areas within groups' home ranges (to avoid their using electric wires or crossing open roads) may be a way to reduce conflict and mortality. This is probably best achieved by an integrated project in which a dedicated and fully mandated conservation body cooperates with local and regional (conservation) authorities and local non-government organizations (NGOs), where needed with international support. It is to be hoped that one of the many local conservation NGOs that have emerged in Sri Lanka in recent years will take up the daunting task of instigating such an initiative.

Acknowledgements. We thank D. Brandon-Jones, S. Bearder, C. Eschmann, S. Jaffe, R. Moore, N. Priston and D. Thurling, who helped in the planning stages, with data collection, and in the write-up of this study. We thank G. de Silva Wijeyeratne, C. Maelge, and A. Samarajeewa of Jetwing Eco Holidays and Jetwing Hotels for support under the Jetwing Research Initiative. For assistance in the field we thank K. Conniff, G. Ash, Bandara, Cyril, Sanjiva, Sunita, Myhse, and S. and P. Perera. We are thankful to People's Trust for Endan- 
gered Species, Party Packs (K. Turner), Oxford Brookes University and the Reinvention Undergraduate Research Scholarship Scheme for funding this project. Two reviewers and M. Bruford provided thoughtful comments on the manuscript. This study formed a part of an MSc in Primate Conservation at Oxford Brookes University by L.P.

\section{LITERATURE CITED}

Brandon-Jones D, Eudey A, Geissmann T, Groves C, Melnick D, Morales D, Shekelle M, Stewart C (2004) Asian primate classification. Int J Primatol 25:97-164

Brooks TM, Mittermeier RA, Mittermeier CG, Fonseca GAB and others (2002) Habitat loss and extinction in the hotspots of biodiversity. Conserv Biol 16:909-923

Buckland ST, Anderson DR, Burnham KP, Laake JL (1993) Distance sampling: estimating abundance of biological populations. Chapman \& Hall, London

$>$ Crusz H (1973) Nature conservation in Sri Lanka (Ceylon). Biol Conserv 5:199-208

Dela JDS (2004) Protecting the endemic purple-faced langur. Loris 23:14-22

Dela JDS (2007) Seasonal food strategies of a colobine frugivore, Semnopithecus vetulus nestor, at Panadura and Piliyandala, Sri Lanka. Int J Primatol 28:607-626

Dela J, Dittus W, Watson A, Gunatillake S, Kodithuwakku N, Liyanage $K$, Weerasinghe N, Wijeyamohan S (2006) Red List: species information on Trachypithecus vetulus nestor. Available at: www.iucnredlist.org/search/ details.php/ 39844/all (accessed on 10 July 2008)

Dittus WPJ (1977) The ecology of a semi-evergreen forest community in Sri Lanka. Biotropica 9:268-286

Eisenberg JF, McKey GM (1970) An annotated checklist of the recent mammals of Ceylon with keys to species. Ceylon J Sci B 8:69-99

Erdelen W (1988) Forest ecosystems and nature conservation in Sri Lanka. Biol Conserv 43:115-135

Eschmann C (2007) An investigation into the calls and behaviours of western purple-faced leaf monkeys (Trachypithecus vetulus nestor) in a suburban environment: a case study from the Talangama Wetlands, Sri Lanka. MSc thesis, Oxford Brookes University, Oxford

Eschmann C, Moore R, Nekaris KAI (2008) Calling patterns of Western purple-faced langurs (Mammalia: Primates: Cercopithecidea: Trachypithecus vetulus nestor) in a degraded human landscape in Sri Lanka. Contrib Zool 77(2):57-65

Forbes M (1840) Eleven years in Ceylon, Vols I \& II. Bentely R, London

Fuentes A, Wolfe LD (2002) Primates face to face: conservation implications of human-nonhuman primate interconnections. Cambridge University Press, New York

Gaidet-Drapier N, Fritz H, Bourgarel M, Renaud PC and others (2006) Cost and efficiency of large mammal census techniques: comparison of methods for a participatory approach in a communal area, Zimbabwe. Biodivers Conserv 15(2):735-754

Groves CP (2001) Primate taxonomy. Smithsonian Institute Press, Washington, DC

Gunatilake HM (1998) The role of rural development in protecting tropical rainforests: evidence from Sri Lanka. J Environ Manage 53:273-292

Haeckel E (1883) A visit to Ceylon. Kegan Paul, Trench \& Co., London

Hill CM (1997) Crop-raiding by wild vertebrates: the farmer's perspective in an agricultural community in Western Uganda. Int J Pest Manag 43:77-84
Hill WCO (1934) A monograph on the purple-faced leaf monkeys (Pithecus vetulus). Ceylon J Sci B 19:23-88

Hladik CM, Hladik A (1972) Disponibilites almentaires et domains vitaux des primates de Ceylon. Terre Vie 2:149-215

IUCN (2006) Red List: species information on Trachypithecus vetulus nestor. Available at: www.iucnredlist.org/search/ details.php/39844/all (accessed on 10 July 2006)

John CS (1795) Beschreibung einiger Affen aus Kasi im nördlichen Bengalen, vom Missionarius John zu Trankenbar. Neue Schr Ges Naturf Freunde Berlin 1:211-218

Kumar A, Konstant WR, Mittermeier RA (1999) Western Ghats and Sri Lanka. In: Mittermeier RA, Myers N, Goettsch Mittermeier C (eds) Hotspots: Earth's biologically richest and most endangered terrestrial ecoregions. CEMEX, Conservation International, Mexico City, p 353-364

Lammertink M, Nijman V, Setiorini U (2003) Population size, red list status and conservation of the Natuna leaf monkey Presbytis natunae endemic to the island of Bunguran, Indonesia. Oryx 37:472-479

Li Y, Huang C, Ding P, Tang Z, Wood C (2007) Dramatic decline of François' langur Semnopithecus francoisi in Guangxi Province, China. Oryx 41:38-43

Mittermeier RA, Valladeras-Padua C, Rylands AB, Eudey A and others (2006) Primates in peril: the world's top 25 most endangered primates 2004-2006. Primate Conserv 20: $1-28$

Mittermeier RA, Ratsimbazafy J, Rylands AB, Williamson L and others (2007) Primates in peril: The world's top 25 most endangered primates 2006-2008. Primate Conserv 22:1-40

Molur S, Brandon-Jones D, Dittus W, Eudey A and others (eds) (2003) Status of South Asian primates: Conservation, Assessment and Management Plan (CAMP) workshop report, 2003. Zoo Outreach Organisation, IUCN/SCC Conservation Breeding Specialist Group-South Asia, Coimbatore

Moore R (2007) Continuing assessment of the conservation status of Sri Lanka's Wet Zone primates with a focus on the Critically Endangered purple-faced leaf monkey (Trachypithecus vetulus nestor). BSc thesis, Oxford Brookes University, Oxford

> Myers N, Mittermeier RA, Mittermeier CG, Gustavo AB, Fonseca DA, Kent J (2000) Biodiversity hotspots for conservation priorities. Nature 403:853-858

Nahallage CAD, Huffman MA, Kuruppu N, Weerasingha T (in press) A report on the distribution of primate species in Sri Lanka. Primate Conserv

Nekaris A, de Silva Wijeyeratne G (2008) Primates of Sri Lanka. Jetwing Eco Holidays, Colombo

Nijman V (2000) Geographical distribution of ebony leaf monkey Trachypithecus auratus (Geoffroy Saint Hilaire 1812) (Mammalia: Primates: Cercopithecidae). Contrib Zool 69:157-177

Nijman V (2004) Effects of habitat disturbance and hunting on the densities and biomass of the endemic Hose's leaf monkey Presbytis hosei (Thomas 1889) (Mammalia: Primates: Cercopithecidae) in east Borneo. Contrib Zool 73:283-291

Paterson JD, Wallis J (2005) Commensalism and conflict: the human-primate conflict. Am Soc Primatologists, Norman, OK

Philips WWA (1981) Manual of mammals of Sri Lanka (Part II), revised edn. Sri Lanka Wildl Nature Protect Soc, Colombo

Pollock JF (2006) Detecting population declines over large areas with presence-absence, time-to-encounter, and count survey methods. Conserv Biol 20:882-892 
Ratnayake J, Abeykoon M, Chemin Y (2001) District-wise forest area variation in Sri Lanka from 1992 to 2001 for supporting the National Physical Planning Policy. Information and Scientific Research Unit National Physical Planning Department, Battaramulla

Ross C, Reeve N (2003) Survey and census method: population distribution and density. In: Setchell JM, Curtis DJ (eds) Field and laboratory methods in primatology; a practical guide. Cambridge University Press, Cambridge, p 90-109

Rudran R (2007) A survey of Sri Lanka's Endangered and endemic western purple-faced langur (Trachypithecus vetulus nestor). Primate Conserv 22:1-6

Santiapillai C, Jayewardene J (1999) Biodiversity conservation in Sri Lanka. Loris 22:4-6

Strayer DL (1999) Statistical power of presence-absence data to detect population declines. Conserv Biol 13:1034-1038

Templeton AR, Shaw K, Routman E, Davis SK (1990) The genetic consequences of habitat fragmentation. Ann Mo Bot Gard 77:13-27

Weerakoon DK (2001) Can the protected area network in Sri Lanka effectively protect biodiversity? Loris 22:2

Zar JH (1999) Biostatistical analysis. Prentice Hall, Upper Saddle River, NJ

Appendix 1. Data collected and questions pertaining to the present study included in the semi-structured interviews

1. Date and location of interview

2. Age and sex of participant

3. Do you ever come into contact with any monkey species? a. If no, go to question 9

4. Can you show me which monkeys live here from these photographs? (sheet with photographs of Macaca sinica, Semnopithecus priam, Trachypithecus vetulus shown)

5. Can you describe the places where these monkeys live?
6. How often do you see them?

7. How many groups live here? How many animals live in each group?

8. How do you feel about there being purple-faced langurs in this area?

9. Can you remember ever seeing monkeys in this area? a. If so, when?

10. Is there any other information you would like to tell me?
Editorial responsibility: Mike Bruford,

Cardiff, UK
Submitted: March 13, 2008; Accepted: May 25, 2008

Proofs received from author(s): July 22, 2008 